\title{
Spatial and temporal characteristics of soil moisture in an intensively monitored agricultural field $\left(\mathrm{OPE}^{3}\right)$
}

\author{
Gabriëlle J.M. De Lannoy ${ }^{a, *}$, Niko E.C. Verhoest ${ }^{a}$, Paul R. Houser ${ }^{b}$, \\ Timothy J. Gish ${ }^{\text {, }}$, Marc Van Meirvenne ${ }^{d}$
}

a Laboratory of Hydrology and Water Management, Faculty of Bioscience Engineering, Ghent University, Coupure links 653, B-9000 Ghent, Belgium

b George Mason University \& Center for Research on Environment and Water, 4041 Powder Mill Road, Suite 302, Calverton, MD 20705-3106, USA

c Hydrology and Remote Sensing Laboratory, USDA-ARS, BARC-West, Beltsville, MD 20705-2350, USA

'Department of Soil Management and Soil Care, Faculty of Bioscience Engineering, Ghent University, Coupure links 653, B-9000 Ghent, Belgium

Received 14 June 2005; received in revised form 16 June 2006; accepted 19 June 2006

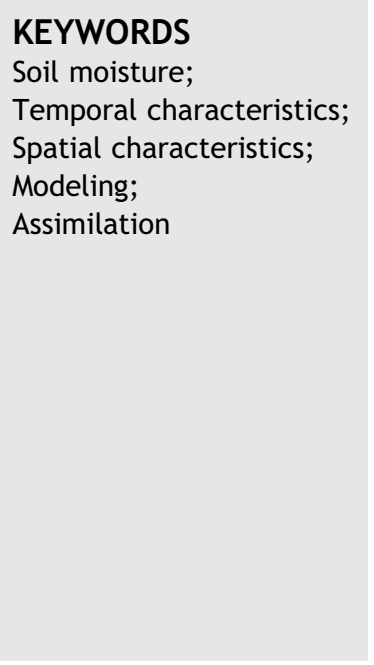

\begin{abstract}
Summary A four-dimensional dataset of soil moisture from the Optimizing Production Inputs for Economic and Environmental Enhancement $\left(\mathrm{OPE}^{3}\right)$ field has been analyzed for temporal and spatial characteristics. Knowledge of soil moisture patterns improves the understanding of processes in the land surface system and helps to identify these processes for use in modeling research. Statistics describing the soil moisture distribution in time showed a lower temporal variability at points in deeper soil layers, except for the deep sensors which were influenced by subsurface flow, where a high temporal variability could be found. The temporal autocorrelation increased with depth in the soil profile. The cross correlation between time series of soil moisture at different points in space decreased with depth and was more variable in deeper soil layers. For the spatial pattern of soil moisture, geostatistical information was extracted from variograms. The evolution of the spatial patterns was dependent on the soil moisture state. In the upper layer, the spatial variability and range increased with increasing soil moisture, while the opposite was found for deeper layers. For deeper layers, the range was mostly limited due to the complex hydrogeology. In this paper, all analyses were related to the needs in modeling and assimilation practices.

(c) 2006 Elsevier B.V. All rights reserved.
\end{abstract}

\footnotetext{
* Corresponding author. Tel.: +32 9264 6140; fax: +32 92646236.

E-mail address: Gabrielle.DeLannoy@lid.kviv.be (G.J.M. De Lannoy).
} 


\section{Introduction}

Since soil moisture is an important state variable of the land surface system, the collection and analysis of soil moisture data at different spatial and temporal scales received a lot of attention. At the regional scale, soil moisture is known to interact with the atmosphere, to influence the climate and its change (Manabe and Delworth, 1990) and to have a controlling function in the hydrological cycle in general. At the field scale, soil moisture has an impact on the generation of runoff and erosion, plant growth and the chemical behavior of fertilizers, which is important to agriculture and environment. Soil moisture itself is influenced by a combination of atmospheric forcings, terrain features, texture and vegetation.

At the field scale, soil moisture values are generally obtained through ground measurements (e.g., Walker et al. (2004)), which are typically point measurements collected in 'representative' locations and at specific time instants. Detailed analysis of soil moisture patterns would require a dense network of observations, which is often impractical. Therefore, remote sensing offers a useful alternative to measuring soil moisture (e.g., Owe et al. (1999), Vinnikov et al. (1999)). However, through these techniques, only the top layer soil moisture is captured and the current data rarely provide any information on detailed field variability. Furthermore, remote sensing data need to be calibrated by ground truth data. Therefore, the collection and use of ground measurements remains a necessity.

Projects for the collection of soil moisture new datasets have been initiated by the need to fully identify the land surface system (Georgakakos and Baumer, 1996). It is through observed soil moisture patterns in space and time that natural processes can be understood and converted into physical laws, empirical relationships and model structures. Once a model structure is set up, observations are needed for parameterization. Since the final model will never be perfect, observations are useful to update the state variables and parameters, if the simulations tend to deviate from the truth. State estimation by a combination of observations and model output is known as data assimilation.

In this study, field scale spatial and temporal characteristics of soil moisture and their importance for modeling are discussed. For this purpose, a four-dimensional dataset from an intensively instrumented agricultural field near Washington DC was used. Several authors (Western and Grayson, 1998; Petrone et al., 2004; Teuling and Troch, 2005) discussed soil moisture characteristics at the field scale, but only a few datasets consist of measurements taken at a high temporal resolution and covering three dimensions in space, i.e., with dense measurements both horizontally over a given study area and vertically over a profile.

In the next section, the data are described. After that, soil moisture observations are analyzed for their temporal and spatial characteristics. Next, the relation between soil moisture observations and terrain features is investigated. Finally, the conclusions from this study are summarized.

\section{Data description}

\section{$\mathrm{OPE}^{3}$ field}

The Optimizing Production Inputs for Economic and Environmental Enhancement $\left(\mathrm{OPE}^{3}\right)$ project is an interdisciplinary research project which started in 1998. This project addresses major environmental and economic issues facing agriculture. The project is managed by the Beltsville Agricultural Research Center (BARC) - Agricultural Research Service (ARS) of the United States Department of Agriculture (USDA). More information on this project can be found on http://hydrolab.arsusda.gov/ope3/.

The project is conducted on a corn field of 21 ha, subdivided into 4 fields, each corresponding to a sub-watershed of approximately 4 ha. The site is situated in Prince Georges County, MD, USA. The 4 sub-watersheds are named A, B, C and $D$ from North to South. The field is located near Greenbelt in the Anacostia watershed, which is part of the Middle Potomac-Anacostia-Occoquan watershed, cataloged by the US Geological Survey (USGS) under Hydrologic Unit Code 02070010. Water draining from the field feeds a wooded riparian wetland and first-order stream, Beaver Dam Creek, which subsequently drains into the Anacostia river, the Potomac river and the Chesapeake Bay.

A Digital Elevation Model (DEM) was constructed (Fig. 1) through interpolation with ordinary kriging (Goovaerts, 1997) of data acquired using a dual frequency, carrier phase real-time kinematic global positioning system (GPS) with a vertical accuracy within $5 \mathrm{~cm}$ (Dulaney et al., 2000). The average height of the obtained DEM is about $40 \mathrm{~m}$ above sea level and the slope is varying from $1 \%$ to $4 \%$.

The major geological formation in the area of the research site dates from the Cretaceous. Each of the subwatersheds of the $\mathrm{OPE}^{3}$ field was formed by sandy fluvial deposits with abundant gravel. Measurements of the top $9 \mathrm{~cm}$ surface texture were spatially interpolated for the 3 texture classes by ordinary kriging. This top soil layer texture can be described as sandy loam according to the USGS soil classification, with an average of $15.62 \pm 1.63 \%$ clay, $22.19 \pm 4.07 \%$ silt and $62.17 \pm 5.56 \%$ sand. A clay layer is present under the entire site, varying from 0.9 to $3.5 \mathrm{~m}$ below the soil surface (Gish et al., 2002). Due to the coarse sand with abundant gravel, the water holding capacity of the deeper layers is very low (10 vol\% or less), and the water contnet only increases due to a rising perched water table or due to preferential flow. Gish et al. (2002) reported that the most important type of preferential flow observed in this site is funnel flow which is gravity driven. This type of subsurface flow forms cascading pathways from one local depression in the clay layer to another. These pathways are temporally dynamic, but spatially constant. In contrast to the deeper layers, the top soil layer has a larger water holding capacity caused by a higher organic matter content (remains of previous crops) and mostly a higher silt fraction than the deeper layers.

Concerning the land use over the last years, the field site itself has changed from an area with limited infrastructure, e.g., roads and little buildings, to an agricultural field. During summer, corn is grown on the OPE ${ }^{3}$ field. The 4 subwatersheds are managed by the BARC-ARS of the USDA, with 

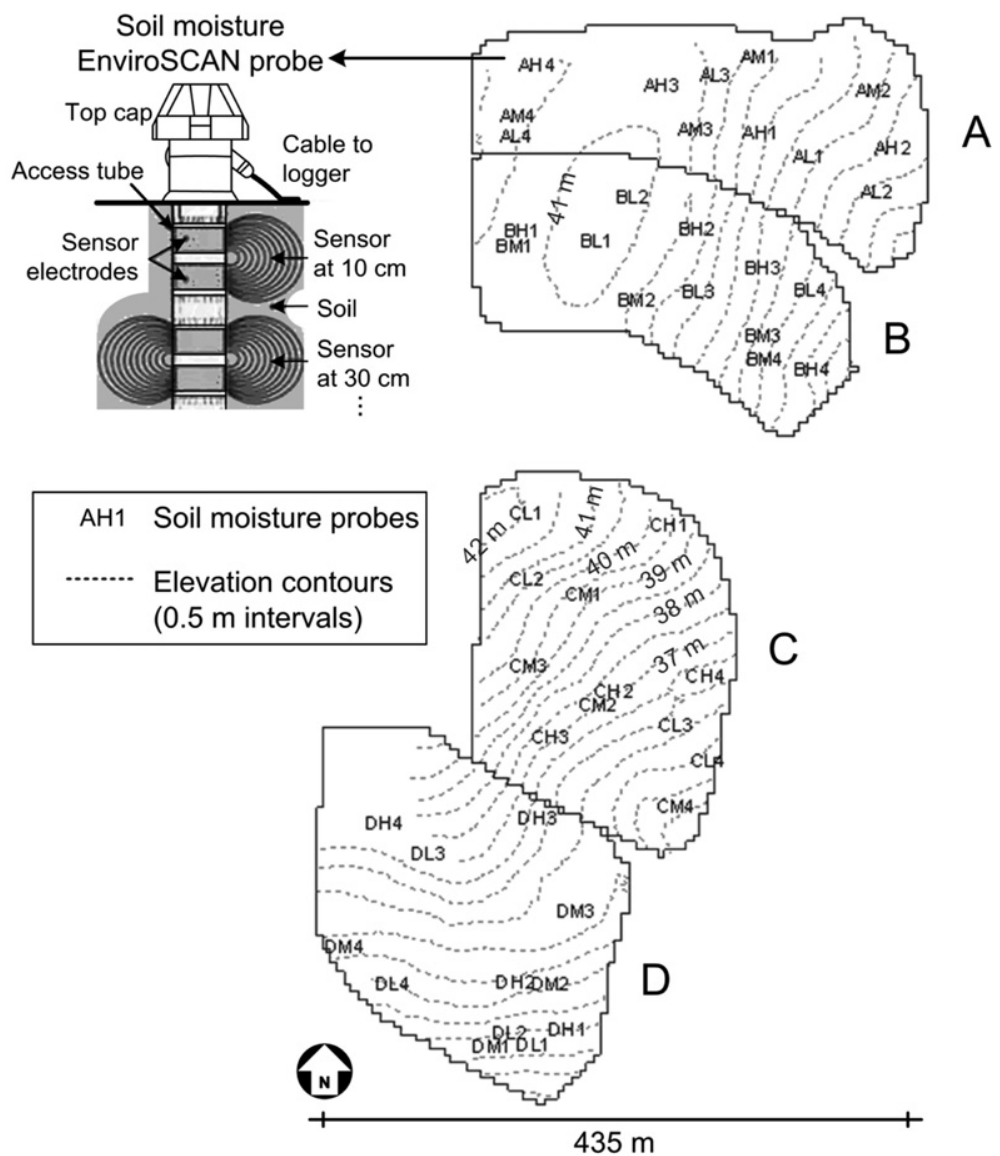

Figure 1 Digital Elevation Model with location of soil moisture probes in the $\mathrm{OPE}^{3}$ field.

different nutrient management practices for the 4 subwatersheds.

\section{Soil moisture measurements}

In each sub-watershed of the $\mathrm{OPE}^{3}$ field, 12 soil moisture probes have been installed (Fig. 1). Capacitance probes (EnviroSCAN, SENTEK Pty Ltd., South Australia) are used to measure volumetric water contents within a $10 \mathrm{~cm}$ radius from the sensor's center (Paltineanu and Starr, 1997; Starr and Paltineanu, 2002). The sampling interval is $10 \mathrm{~min}$ and for this study, data collected from May 1, 2001 to May 1, 2002 were analyzed. To compare data and model results in a further stage, a transformation was performed on the observations to change the aggregation time from $10 \mathrm{~min}$ to $1 \mathrm{~h}$ by averaging. It should be indicated that the summer of 2001 was exceptionally wet.

The probes are named following a 3 digit system. The first letter represents the name of the sub-watershed $(A$, $B, C, D)$, the second letter $(L, H, M)$ refers to the estimated infiltration rate at the point of installation (Low, High, Moderate) and the third digit $(1,2,3,4)$ discerns between the different probes of a specific infiltration regime. This labeling was introduced by Gish et al. (2002) and was based on a subdivision of the field into areas with different response to a ground-penetrating radar (reflecting the depth to the clay layer) and differences in slope. H-probes have sensors at 10 , 30 and $80 \mathrm{~cm}$. L- and $M$-probes have sensors at 10, 30, 50,
120,150 and $180 \mathrm{~cm}$. L-probes have an additional sensor at $80 \mathrm{~cm}$ depth. During the study period, probes AL3, AL4, $\mathrm{AM} 3, \mathrm{AM} 4, \mathrm{AH} 3, \mathrm{AH} 4, \mathrm{CL} 3, \mathrm{CL} 4, \mathrm{CM} 3, \mathrm{CM} 4, \mathrm{CH} 3$ and $\mathrm{CH} 4$ were not operational because of technical defects (hit by lightning), causing that 36 out of 48 probes remained operational.

\section{Temporal characteristics}

\section{Descriptive temporal statistics}

The temporal average and standard deviation at the individual sensors describe the overall wetness and the response of the soil system to meteorological conditions and to influences from neighboring soil volumes. This kind of information is interesting for calibration and validation of land surface models, as selection of model parameters is often based on the optimization of objective functions, which include a comparison between temporal statistics from observed and modeled soil moisture time series.

Fig. 2 shows the temporal average versus the standard deviation of soil moisture for all sensors in the $\mathrm{OPE}^{3}$ field. For the measurements at $10 \mathrm{~cm}$ depth, the range in the temporal soil moisture averages for the different sensors is smaller than what is observed for deeper layers. As the top soil layer is exposed to a spatially constant atmospheric forcing and is little influenced by groundwater, the temporal average soil moisture at the individual sensors will differ 

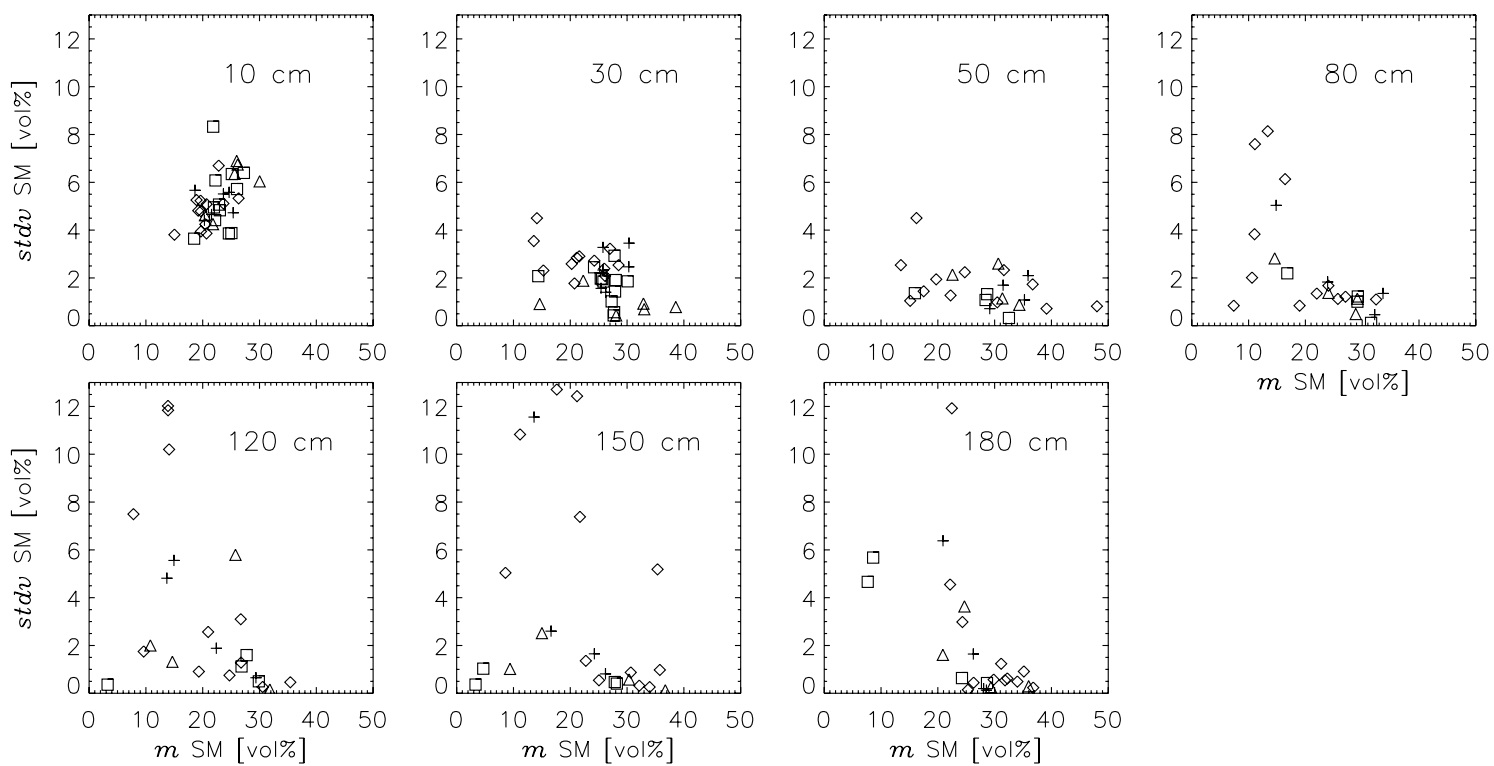

Figure 2 Standard deviation ( $s t d v)$ in time versus temporally averaged soil moisture $(m \mathrm{SM})$ for all sensors in the OPE ${ }^{3}$ field during the period May 1, 2001 to May 1, 2002. (+: field A, $\diamond:$ field B, $\triangle$ : field C, $\square$ : field D).

little. For some profiles, deeper layers easily drain due to their large granular structure, resulting in lower moisture contents, whereas for other places with a shallow groundwater table, wetter conditions may occur due to capillarity, resulting in a wider range of temporally averaged values over all sensors in deeper layers. Further, in deep soil layers $(150$ and $180 \mathrm{~cm})$ soil moisture nearly remains the same (i.e., wet when the groundwater table resides near the considered layer or dry if soil water drains to deeper layers) resulting in low standard deviations. However, at some sensors, the groundwater table temporarily fluctuates due to the build up of a perched water table caused by preferential (funnel) flow, followed by a slow emptying (i.e., drying out at $120 \mathrm{~cm}$ first, then at $150 \mathrm{~cm}$ and finally at $180 \mathrm{~cm}$ ), probably as a response to evapotranspiration or at some places through leakage through the clay layer. Since at these sites the soil moisture switches a couple of times during a year between two states (nearly saturated and very dry, which is clearly demonstrated in Fig. 4 for probes BL1 and BL2 at $150 \mathrm{~cm}$ ) the standard deviation of the moisture contents, calculated on year basis will be large.

Through calculation of the autocorrelation for increasing time lags of the daily averaged time series of soil moisture for all sensors at all depths, the characteristic time scale was determined. See Fig. 3 for an example of these functions at different depths for probes $A M 1$ and BL4, which are quite representative. It was found that, on average, the autocorrelation reaches an almost constant value (i.e., shows stationarity) for time lags of approximately 50 days (i.e., visually where the graph is flattening out or numerically by three times the temporal autocorrelation length - see below-) for soil moisture at 10, 30 and $50 \mathrm{~cm}$ depth. At deeper layers, a slight increase of the characteristic time scale was observed, with 100 days at $80 \mathrm{~cm}$ depth and 130 days or more for 120 and $150 \mathrm{~cm}$ depth.
Yet, for individual sensors, large deviations towards these values can be found. This can be attributed to the different hydrological processes, e.g., preferential flow, which occur at each of the sensors. The increase in the characteristic time scale for deeper soil layers is very plausible, since the upper layer soil moisture is strongly influenced by the stochastic precipitation input and evapotranspiration, whereas for deeper soil layers, soil moisture changes more slowly. In Table 1, some statistics of the correlation length are shown for all available sensors at the different depths. The correlation length was determined as the time lag for which the correlation becomes $1 / e(e=2.71828 \ldots)$. The correlation length is about 2 weeks in the rooting zone $(10$ and $30 \mathrm{~cm}$ ) and up to 2 months in the deepest layer. This is comparable to what Skøien et al. (2003) found from temporal variograms for soil moisture averaged over the upper $30 \mathrm{~cm}$.

\section{Cross correlation}

Information on the cross correlation between soil moisture at different points in space is of particular interest for spatial modeling. A model can explicitly account for cross correlation, e.g., by allowing horizontal redistribution of water. For state updating, the knowledge of cross correlation between different points is very interesting to understand the propagation of information from one point to another. The computational load of state updating can be limited by considering only those points that are highly correlated with the observation point, i.e., by localization (see Section "Relation of soil moisture to terrain features").

To estimate the degree to which two time series of soil moisture are correlated, the cross correlation with zero time lag was calculated over the complete time series of 1 year. Only cross correlation between sensors at the same 

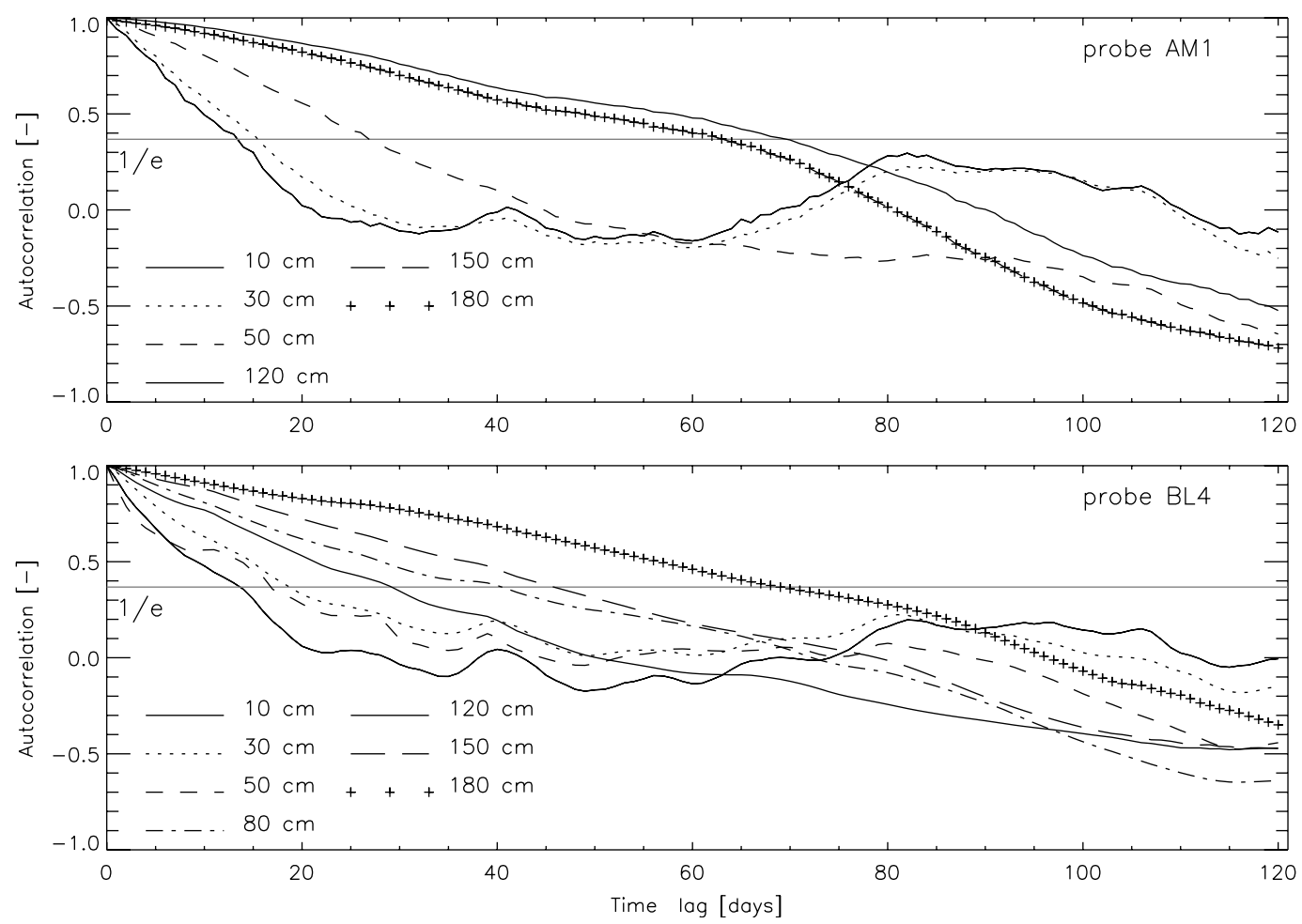

Figure 3 Temporal autocorrelation of soil moisture for probes AM1 and BL4 at all depths. Remark that the autocorrelation function at 150 and $180 \mathrm{~cm}$ depth are overlapping for probe AM1.

Table 1 Median $M$, minimum min, maximum max, mean $m$ and standard deviation std $v$, all expressed in days, of the temporal autocorrelation length, determined for all available $(N)$ sensors per depth

\begin{tabular}{|c|c|c|c|c|c|c|c|}
\hline Depth & $10 \mathrm{~cm}$ & $30 \mathrm{~cm}$ & $50 \mathrm{~cm}$ & $80 \mathrm{~cm}$ & $120 \mathrm{~cm}$ & $150 \mathrm{~cm}$ & $180 \mathrm{~cm}$ \\
\hline$M$ & 16 & 16 & 18 & 36 & 45 & 46 & 71 \\
\hline $\min$ & 8 & 11 & 14 & 17 & 16 & 20 & 19 \\
\hline $\max$ & 59 & 54 & 61 & 77 & 98 & 117 & 82 \\
\hline$m$ & 16 & 19 & 26 & 40 & 51 & 57 & 58 \\
\hline$s t d v$ & 10 & 9 & 13 & 15 & 20 & 24 & 21 \\
\hline$N$ & 36 & 36 & 24 & 24 & 24 & 23 & 22 \\
\hline
\end{tabular}

depths is discussed. The values from the correlation matrices at some individual observation depths for the entire 1 year time series are plotted in Fig. 7 as function of several variables (which are of no importance for this section, but will be discussed in Section "Relation of soil moisture to terrain features"'). In general, the correlation coefficients are quite high. The correlation between sensors tends to be smaller at deeper layers, where the spread on the cross correlation increases. High cross correlations mean that sensors react similarly on inputs and that no side effects influence the soil moisture response. Low correlations indicate that the soil moisture response at some times may be different because of varying conditions, including depth to the clay layer, occurrence of preferential flow, existence of a perched water table, etc., that induce different responses. This is illustrated for the sensors at 10 and $150 \mathrm{~cm}$ depth in Fig. 4. For $10 \mathrm{~cm}$, depth all sensors respond similarly, because their moisture content is mainly influenced by atmospheric forcings. At deeper layers there is less similarity, as they are subjected to different hydrologic conditions (e.g., depth to the water table) and processes (e.g., preferential flow). In the next section, it will be shown that the cross correlation is inversely related to the coefficient of variation in space.

\section{Spatial characteristics}

Investigation and use of the spatial pattern of soil moisture is getting more attention with the increase in the availability of remote sensing data. Knowledge of the spatial structure is important in the development and calibration of 3D hydrological models (Refsgaard, 2000; Grayson et al., 2002) and in data assimilation studies.

\section{Descriptive spatial statistics}

In Fig. 5, the average spatial soil moisture at different depths over the whole $\mathrm{OPE}^{3}$ field, the standard deviation in space and the coefficient of variation are plotted. In 

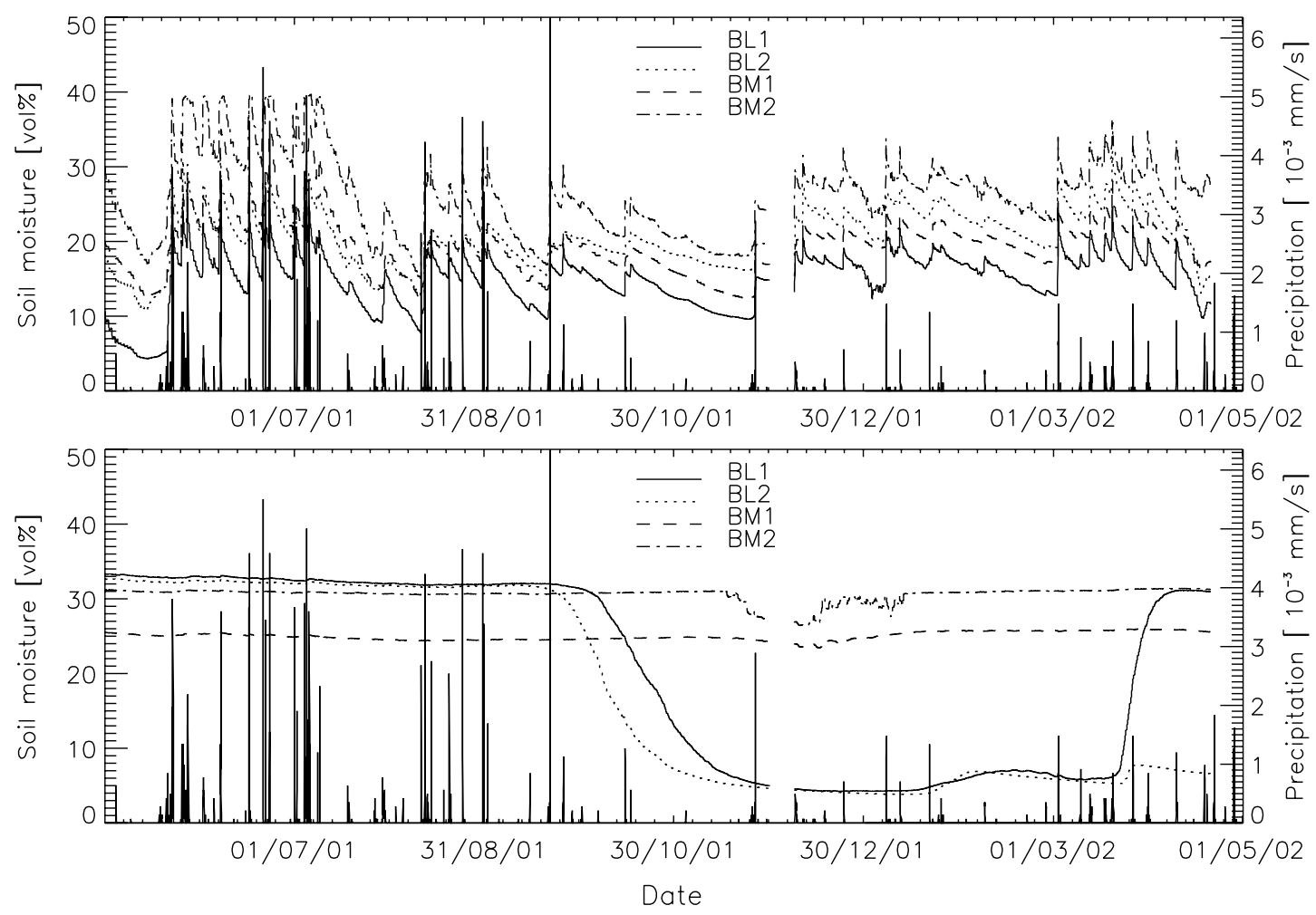

Figure 4 Time series of soil moisture for some sensors at 10 and $150 \mathrm{~cm}$ depth in field B for 1 year in $2001-2002$.

the calculation of the spatial statistics, a maximum of only one missing sensor (of the 36 working sensors) was allowed.

For the upper layer at $10 \mathrm{~cm}$ depth, the soil moisture map mostly shows more spatial variability at higher moisture contents than at lower moisture values. The time series show peaks in spatial standard deviation, when the soil moisture is higher. During the wet summer of 2001, the variability reaches maximal values and does not further increase with increasing soil moisture. The scatter plot contains of a number of dry-out events, with varying spatial variability for similar spatially averaged soil moisture contents, so that no average general trend can be found. It is interesting to see that during the late summer and beginning autumn of 2001, where repeated periods of dry-outs occurred, the coefficient of variation starts to increase, once the soil is drying out, although the standard deviation does not alter much. This can be attributed to the fact that due to spatial differences in evapotranspiration, the dryout rate will not be spatially constant, causing that the standard deviation on the soil moisture decreases less rapidly than its mean value. At soil moisture peaks, also the coefficient of variation peaks, together with the standard deviation.

At and below $50 \mathrm{~cm}$, the spatial standard deviation and coefficient of variation increase with decreasing areal soil moisture, most clearly in the wet summer period of 2001. At $30 \mathrm{~cm}$ depth, the standard deviation shows a behavior that contains features of the upper layer at $10 \mathrm{~cm}$ as well as of the lower layers at and below $50 \mathrm{~cm}$ : sometimes an increase in standard deviation with increase in spatially averaged soil moisture is found and sometimes a decrease is observed. Clearly, soil moisture in the upper layers, includ- ing the rooting depth, shows a different temporal variation of the spatial variability than the deeper layers. Further, the spatial standard deviation and the coefficient of variation are larger in deeper layers than in upper layers at all times. The limited coefficients of variation near the surface and the high coefficients of variation for deeper layers, respectively, explain the high and low values for the cross correlation for the surface and deep layers, in Section "Cross correlation"'. This reveals that accurate quantification of the sub-surface soil water dynamics is a difficulty in the OPE ${ }^{3}$ field.

Based on the reasoning of Grayson et al. (1997), it can be argued that the decrease in the standard deviation with increasing spatially averaged soil moisture in the $\mathrm{OPE}^{3}$ field for deeper layers is due to lateral redistribution of water. At $10 \mathrm{~cm}$ depth, an increase in the standard deviation with wetness is due to precipitation, which is possible as long as no saturation is reached. Note that similar findings were reported by several authors (Robinson and Dean, 1993; Famiglietti et al., 1998), whereas a decrease in spatial variability with increasing soil moisture was found by Famiglietti et al. (1999). The wet state at the surface is thus dominated by a vertical flux (local control) that can be quite random in space: vegetation causes a variable interception and the presence of rows in the corn field creates an additional variability between row and inter-row areas (Van Wesenbeek and Kachanoski, 1988). Under dry conditions at the surface, there is a spatially almost constant boundary condition determined by atmospheric forcings, which cause evapotranspiration. Because the evapotranspiration rate decreases with decreasing moisture content, the moisture content of wetter soils will decrease faster than for dryer 

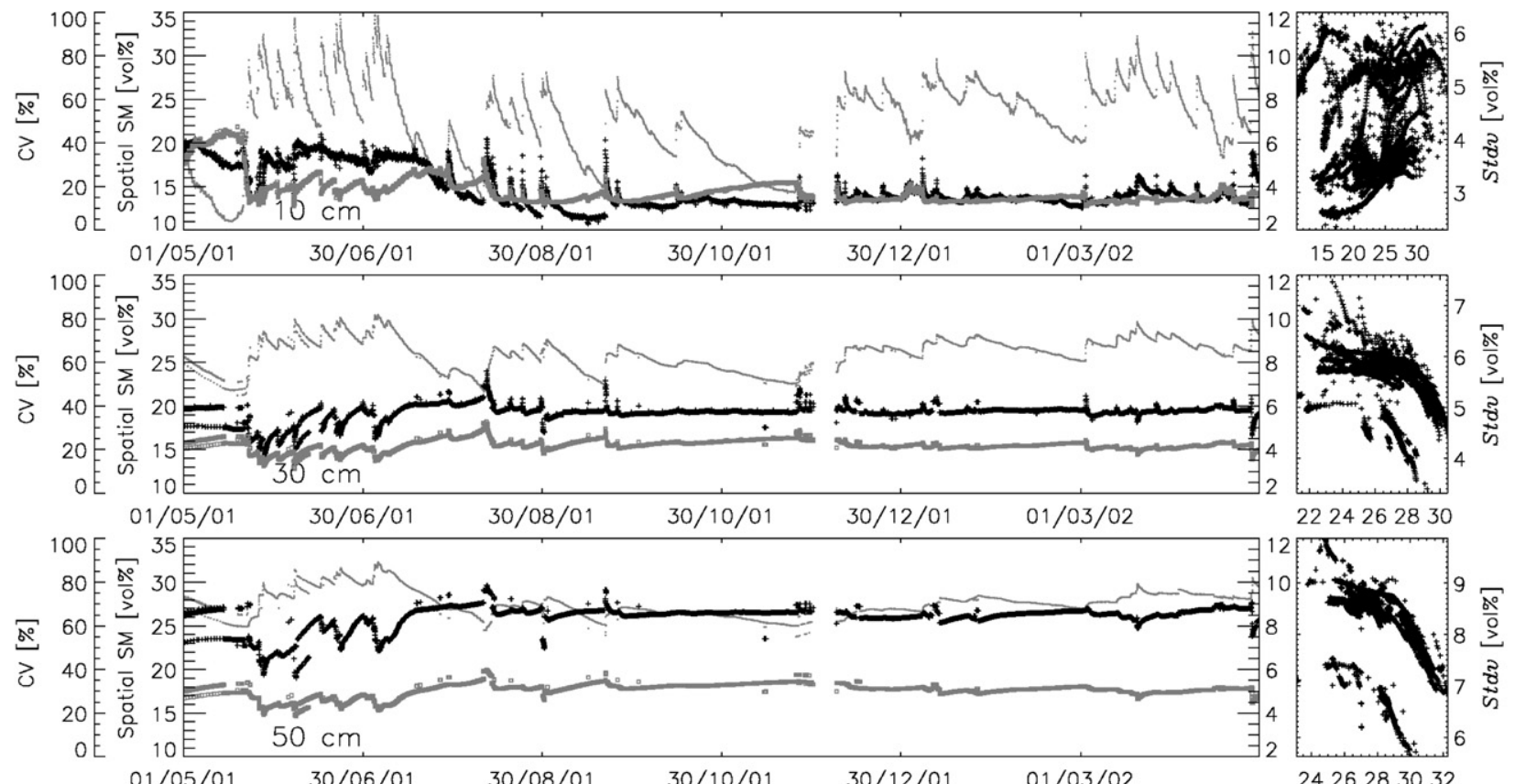

2224262830
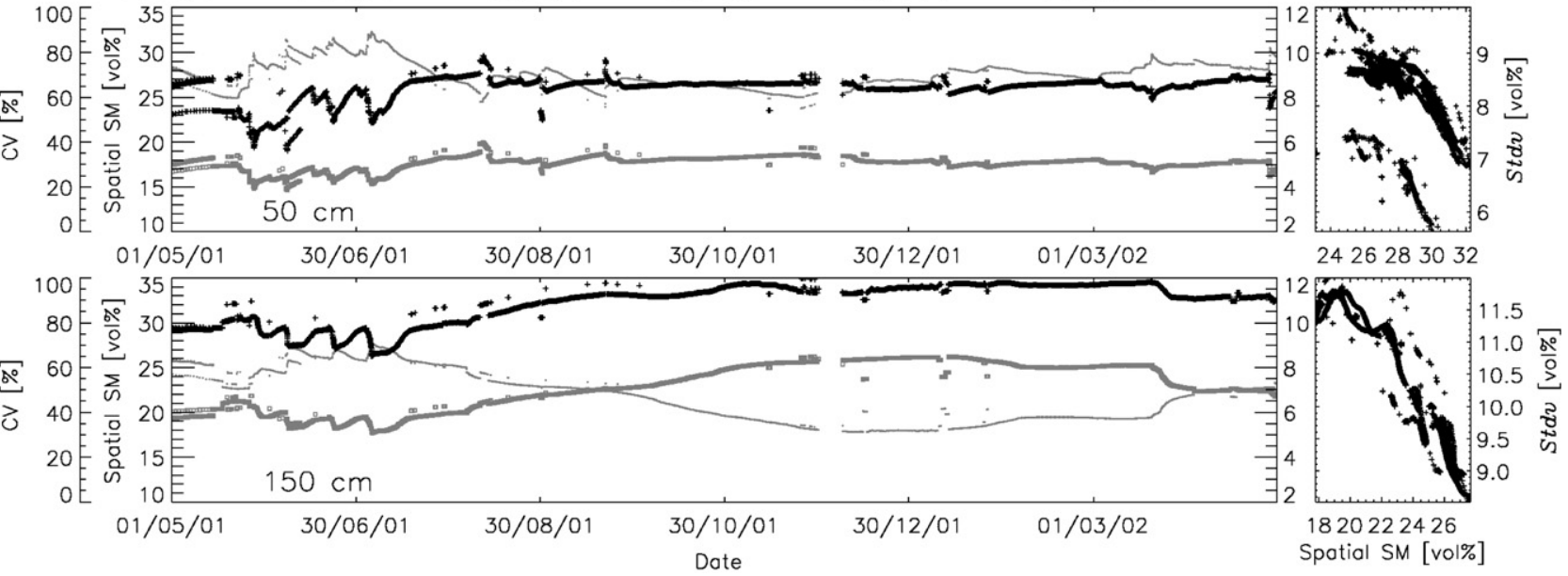

Figure 5 Spatial average soil moisture SM (thin gray, left vertical scale), standard deviation stdv (black +, right vertical scale) and coefficient of variation CV (gray $\square$, extra left vertical scale) at different depths for all sensors in the OPE ${ }^{3}$ field during the period May 1, 2001 to May 1, 2002. The right hand side figures plot the standard deviation, observed at the different time steps, in function of the spatial average soil moisture at the corresponding time steps.

soils. As a result, the spatial variability will decrease during dry-out. These observations confirm recent studies indicating that surface soil moisture variability shows a concave pattern with mean soil moisture (Albertson and Montaldo, 2003; Ryu and Famiglietti, 2005).

General spatial statistics, averaged over the time series of 1 year, are summarized in Table 2 . While Wilson et al. (2004) found that the temporal variation in soil moisture was 5 times the spatial variation, in the $\mathrm{OPE}^{3}$ field the tem- poral (see Fig. 2) and spatial variation (see Table 2) have the same magnitude.

\section{Spatial correlation}

\section{Method}

For the practical assessment of the spatial correlation, at each observation time, omni-directional variograms were calculated (with a lag resolution of $20 \mathrm{~m}$ to allow for some

Table 2 Overview of the time-space averaged soil moisture $m$ [vol\%] and the standard deviation in space, averaged over time, $s t d v$ [vol\%] on the spatially averaged soil moisture for hourly data from May 1, 2001 to May 1, 2002 for the four sub-watersheds (A, $B, C, D$ ) individually and for the complete $\mathrm{OPE}^{3}$ field (All)

\begin{tabular}{|c|c|c|c|c|c|c|c|c|c|c|}
\hline \multirow[t]{2}{*}{ Depth } & \multicolumn{2}{|l|}{ A } & \multicolumn{2}{|l|}{ B } & \multicolumn{2}{|l|}{$C$} & \multicolumn{2}{|l|}{$D$} & \multicolumn{2}{|l|}{ All } \\
\hline & $m$ & $s t d v$ & $m$ & $s t d v$ & $m$ & $s t d v$ & $m$ & $s t d v$ & $m$ & $s t d v$ \\
\hline $10 \mathrm{~cm}$ & 22.32 & 3.23 & 20.55 & 3.13 & 24.99 & 3.67 & 23.34 & 3.53 & 22.47 & 3.86 \\
\hline $30 \mathrm{~cm}$ & 28.42 & 2.38 & 22.14 & 4.93 & 30.85 & 6.90 & 26.50 & 4.08 & 25.98 & 5.67 \\
\hline $50 \mathrm{~cm}$ & 32.94 & 2.84 & 21.70 & 6.57 & 34.51 & 12.02 & 28.05 & 5.69 & 27.55 & 8.36 \\
\hline $80 \mathrm{~cm}$ & 26.35 & 8.04 & 17.84 & 6.79 & 19.32 & 10.21 & 25.39 & 5.98 & 21.97 & 8.32 \\
\hline $120 \mathrm{~cm}$ & 20.10 & 6.43 & 17.88 & 7.56 & 22.77 & 10.29 & 21.33 & 9.85 & 20.14 & 9.08 \\
\hline $150 \mathrm{~cm}$ & 20.16 & 6.78 & 22.66 & 8.88 & 27.51 & 11.60 & 19.45 & 11.95 & 21.70 & 10.85 \\
\hline $180 \mathrm{~cm}$ & 25.08 & 3.67 & 28.50 & 5.47 & 30.46 & 5.72 & 22.50 & 9.38 & 26.11 & 7.82 \\
\hline
\end{tabular}


averaging). After some tests for several variogram models at some individual time steps, it was decided to fit exponential variogram models (as in Western et al. (1998)) to the experimental semivariance values:

$\gamma(h)=C_{l}\left[1-\exp \left(\frac{-3 h}{a}\right)\right]$

where the range $a$ and the sill $C_{l}$ were sought by least squares minimization of the error between the observed and the fitted variogram. The sill $C_{l}$ is the level at which the variogram flattens out and the range $a$ is the distance beyond which the correlation between points is minimal. The nugget (representing small scale variability and measurement errors) was not included to reduce the computational load for automated fitting, since it was found experimentally that this value was very low.

Western et al. (2004) studied the variation in variogram parameters for 6-8 time instants over 2 years in different catchments. They found that spatial variance and thus also the sill and, to a lesser extent, the correlation length were related to the mean soil moisture. Their study of variograms was based on many points in space and thus probably yielding more accurate estimates of parameters than obtained for the $\mathrm{OPE}^{3}$ soil moisture measurements. However, the strength of the application to the $\mathrm{OPE}^{3}$ field measurements lies in the nearly continuous time series of measurements, which revealed more clearly the evolution of the variogram parameters in time. Inclusion of the dynamic behavior of the spatial structure during system identification is expected to improve modeling and data assimilation results, i.e., the propagation in time of the state uncertainty at each location can be achieved more accurately by well defined model dynamics, as was illustrated in meteorology by e.g., Bouttier (1994).

\section{Results}

The change in parameters of the fitted variograms for different soil depths of the whole $\mathrm{OPE}^{3}$ field over the complete time series of 1 year, is shown in Fig. 6. These parameters are clearly varying with the soil moisture content in time. Evidently, the evolution of the sill is completely linked with the evolution of the spatial variance (see spatial standard deviation in Section "Descriptive spatial statistics"). At $10 \mathrm{~cm}$ depth, the range of the fitted variogram is very variable and evolves proportionally to moisture: the wetter, the larger the range. The range is around $200 \mathrm{~m}$ and during the
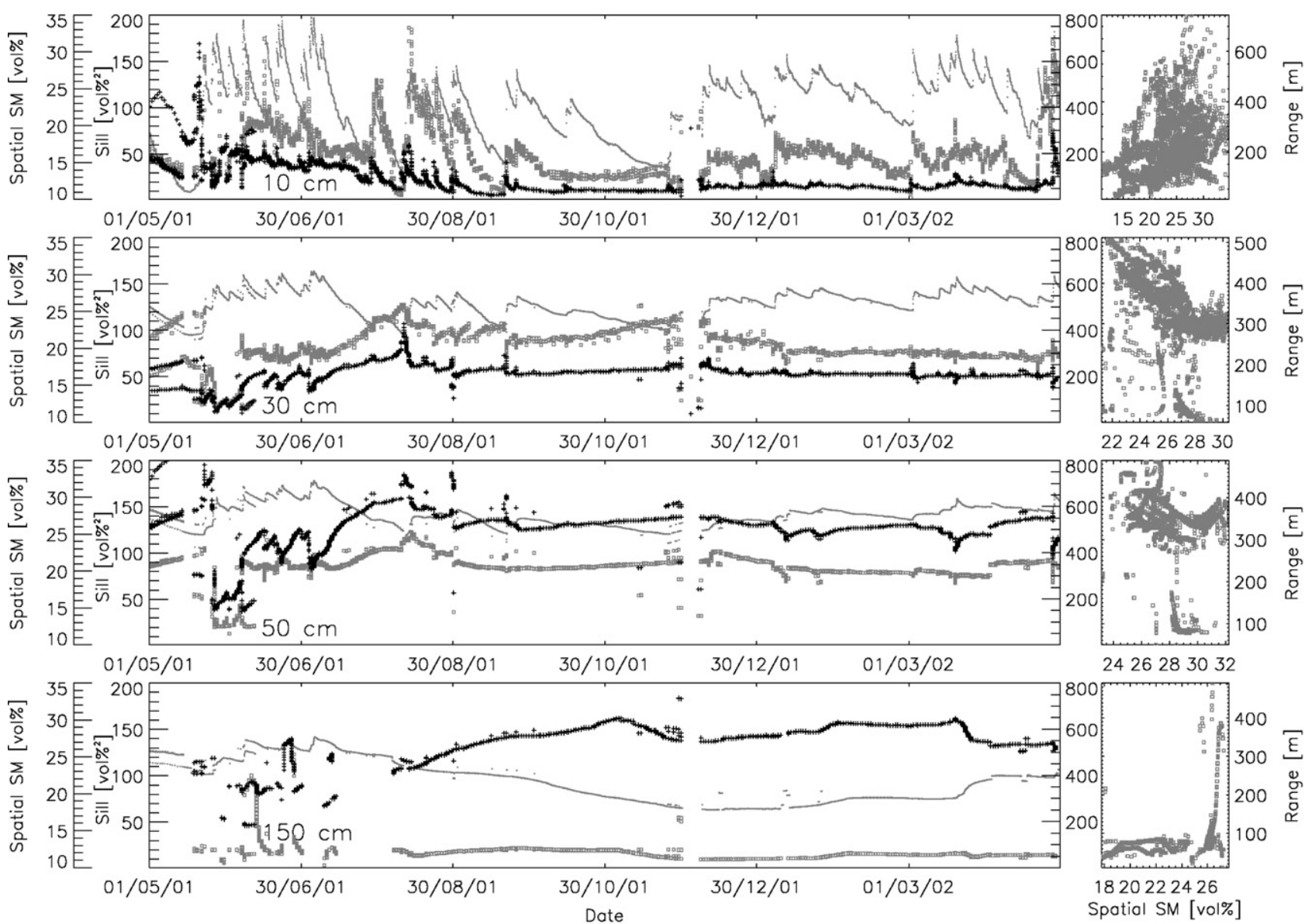

Figure 6 Time series of variogram parameters (range and sill in gray $\square$ and black +, with right and left vertical scale, respectively) and spatially averaged soil moisture SM (thin gray, extra left vertical scale). Some spurious points are caused by missing sensors, which affects the estimation of the geostatistical parameters. At $150 \mathrm{~cm}$ depth, variogram fitting was not always possible, which results in missing parameters. The righthand side figures plot the range, observed at the different time steps, in function of the spatial average soil moisture at the corresponding time steps. 
wet summer of 2001, the range reaches $300 \mathrm{~m}$ and more. During dry periods, vertical fluxes, i.e., evapotranspiration, regulate the soil moisture values in the upper soil layer, and the range decreases. Under very dry conditions, the structure and variability in space is very low and the shapes of the variogram tend to suggest a pure random nugget effect. During wet periods with a vertical flux of precipitation, the range increases, which means that the precipitation (throughfall) values might be higher correlated than the evapotranspiration in space and that the soil moisture pattern becomes more organized, e.g., due to a pattern in texture (different hydraulic conductivities) and a structure in the runoff routing. The range reaches about $300 \mathrm{~m}$ at $30 \mathrm{~cm}$ and $50 \mathrm{~cm}$, and from $80 \mathrm{~cm}$ depth onwards, the range values decrease with depth. This can be attributed to the complex hydrogeology with different processes occurring at different locations.

Except for the geostatistical parameters at $30 \mathrm{~cm}$ depth, the range and the sill evolve similarly in time: at a given depth, a higher variability is observed together with a larger range. Over the profile, it is found that (independent of the time) at deeper depths high sills and low ranges are found. Of course for all findings, it is assumed that the best variogram model remains always exponential, which may not always be the case.

For simplicity, several state estimation techniques assume a time invariable static correlation structure of the variables. To obtain such a single indicative value for the sill and range over the entire time period studied, pooled stratified (in time) variograms are proposed. Semivariogram values were calculated at each time step (stratification in time) and all obtained variograms during the study period were pooled to end up with multiple semivariance values at each lag. Then, an exponential variogram model was fitted to all these observed values. Because of the large spread in semivariance values at larger lags, the fitting for these pooled variograms was limited to the values for the first $200 \mathrm{~m}$ only. In Table 3, geostatistical parameters for pooled stratified variograms over 1 year for the whole $\mathrm{OPE}^{3}$ field are summarized for variograms calculated with a lag interval of $20 \mathrm{~m}$ (similar for other lag intervals). Note that for an exponential variogram, the numerical value of the range is three times the correlation length. Integrated over time, the sill is lower $\left(15-40\right.$ vol $\left.{ }^{2}\right)$ for upper layers than for lower layers (around 100 vol $\%^{2}$ ) and the correlation length reaches maximal values around $70 \mathrm{~m}$ at $30 \mathrm{~cm}$ and decreases with depth to values less than $20 \mathrm{~m}$. Remark that the temporally averaged spatial standard deviations (and hence the variances) in Table 2 show the same tendency as the sill values, which indicates that the variogram fitting was quite accurate.

\section{Relation of soil moisture to terrain features}

For modeling purposes, it is advantageous to link the variability in soil moisture to differences in terrain. The relationship between soil moisture for all sensors at all depths in the $\mathrm{OPE}^{3}$ field and texture, elevation and the topographic index (Beven and Kirkby, 1979) at all probe locations was studied. It is not possible to conclude that spatial patterns of temporal statistics (mean, standard deviation, spatially averaged cross correlation and standard deviation on it) of soil moisture are in any way dependent on topography or surface texture in the $\mathrm{OPE}^{3}$ field. However, the spatial soil moisture pattern at each individual time step can often be related to terrain features, but this relationship is different for each time period.

As stated in Section "Cross correlation", knowledge of the cross correlation is of major importance in data assimilation applications. If the cross correlation between points can be linked to a different in static terrain features, this is even more simple for modeling purposes. Until now, mostly the relation between cross correlation and distance was explored (e.g., Houser et al. (1998)). The relation between the cross correlation between time series of sensors with zero time lag and the distance, height difference, texture difference and time averaged soil moisture difference between sensors is presented in Fig. 7 for the entire period of data. There is a clear decrease in cross correlation for increasing terrain differences between sensors. For an increasing difference in topographic indices calculated at any DEM resolution, there is hardly a decreasing trend in correlation (data not shown).

A gradient-expansion algorithm was used to compute a non-linear least squares fit of a simple exponential function to the observed relation between correlation and difference in terrain features:

$$
r(h)=\exp \left(-\frac{|h|}{L_{E}}\right)
$$

with $|h|$ the absolute difference in distance or difference in terrain characteristics. Since the calculated correlation coefficients are very high and a simple exponential function only reaches the correlation length at $1 / e$, the correlation length $L_{E}$ takes rather high values (see Table 3 ).

Table 3 Geostatistical parameters describing the spatial structure of observed soil moisture over the whole OPE ${ }^{3}$ field

\begin{tabular}{lrrrrrrr}
\hline Depth & $10 \mathrm{~cm}$ & $30 \mathrm{~cm}$ & $50 \mathrm{~cm}$ & $80 \mathrm{~cm}$ & $120 \mathrm{~cm}$ & $150 \mathrm{~cm}$ & $180 \mathrm{~cm}$ \\
\hline Sill $\left(\right.$ vol\% $\left.{ }^{2}\right)$ & 17 & 37 & 72 & 67 & 93 & 119 & - \\
Range $(\mathrm{m})$ & 143 & 201 & 139 & 53 & 53 & 37 & - \\
Correlation length $(\mathrm{m})$ & 48 & 67 & 46 & 18 & 18 & - & 12 \\
Correlation length $L_{E}(\mathrm{~m})$ & 1977 & 1988 & 1162 & 748 & 808 & 280 & 162 \\
Correlation length $L_{S}(\mathrm{~m})$ & 604 & 610 & 432 & 310 & 333 & 59 \\
\hline
\end{tabular}

The range and sill are derived from fitting an exponential variogram to the pooled (over 1 year) stratified (in time) semivariance values. The upper correlation length is calculated as the range/3. The correlation lengths $L_{E}$ and $L_{S}$ are the parameters of the simple exponential and the SOAR, respectively, that are fitted to the cross correlations (integrated over time) versus distance between sensors. 

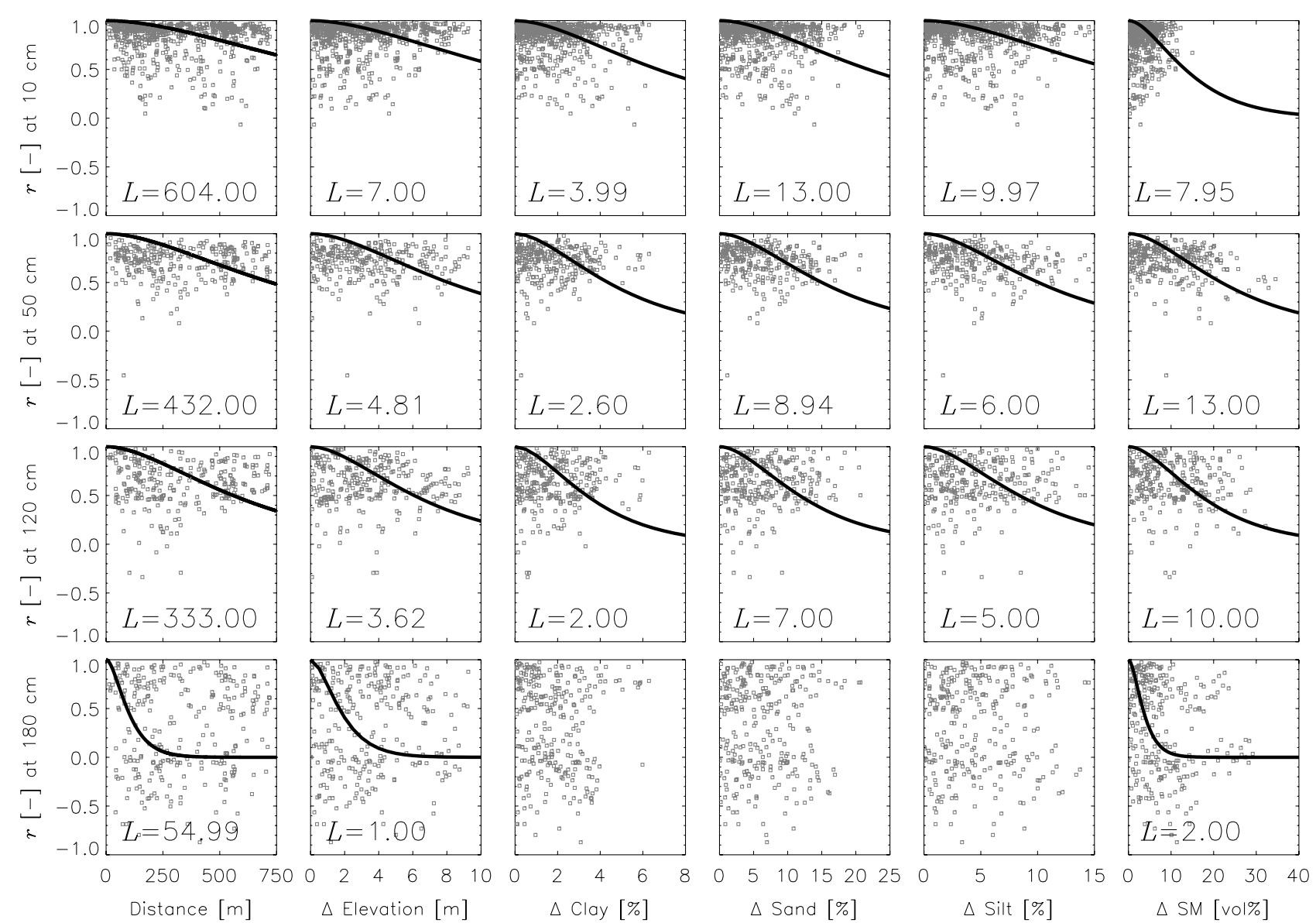

Figure 7 Relation between cross correlation $(r)$ between time series and distance between sensors, difference in height $(\Delta$ Elevation), texture difference ( $\Delta$ Clay/Sand/Silt) and difference in wetness $(\Delta S M)$ between sensors in the whole OPE ${ }^{3}$ field over the period of May 1, 2001 to May 1, 2002. The correlation length $L_{S}$ is for the fitted SOAR (-), where fitting was possible. Note that texture is sampled from the top $9 \mathrm{~cm}$ for each plot.

To avoid spurious long range correlations from having any impact on the propagation of assimilated information, several authors (Hamill et al., 2001) used a localized correlation structure. To determine a correlation length for localization, a compactly supported second order autoregressive (SOAR) function (Gaspari and Cohn, 1999) was fitted:

$r(h)=\left(1+\frac{|h|}{L_{s}}\right) \cdot \exp \left(-\frac{|h|}{L_{s}}\right)$

The parameter $L_{s}$ represents the correlation length and is indicated in Fig. 7. The correlation length $L_{s}$ is the distance where the correlation reduces to $2 / e$ and where the defined correlation function shows a point of inflection. Note that $|h|$ and $L_{s}$ are only real 'length' [m] measures when the evolution of the correlation with distance is studied (first column of the plots). The units of this measure $L_{s}$ vary with the difference considered. For the $O \mathrm{PE}^{3}$ field, it can be concluded that the correlation length decreases with depth and that this parameter is clearly higher in winter than in summer for all depths (not shown). In the summer, the field is covered with corn, which may contribute to the variability and cause a shorter correlation length. The correlation length for the whole $\mathrm{OPE}^{3}$ field decreases with depth for $L_{s}$ from around $600 \mathrm{~m}$ at the upper layer to $50 \mathrm{~m}$ at deeper layers for distance (see also Table 3), 8 to $2 \mathrm{~m}$ for height, 4 to $1 \%$ for clay, 13 to $1 \%$ for sand, 10 to $1 \%$ for silt and 7 to 2 vol\% for soil moisture difference. Remark that in Table 3, one spatial correlation length is based on pooled stratified variograms (spatial correlation), while correlation lengths $L_{E}$ and $L_{S}$ are based on a fit to (temporal) cross correlations versus distance. Some care is advised in the interpretation of the correlation lengths, because they depend on the chosen structure of the correlation function.

\section{Conclusions}

In order to understand field processes related to soil moisture in the land surface system, ground measurements of soil moisture provide invaluable information. From a fourdimensional dataset of soil moisture observations in the $\mathrm{OPE}^{3}$ field site of the BARC-ARS (USDA) in Beltsville (USA), temporal and spatial characteristics were extracted to describe the patterns of soil moisture. For 36 profiles in a field of 21 ha, 1 year (May 1, 2001 through April 30, 2002) time series at 3-7 depths were analyzed.

From the distribution of soil moisture in time, it was found that the temporal variability decreases with soil depth. For the upper soil layer the temporal standard deviation increased with temporally averaged soil moisture, while the opposite was true for deeper layers, due to 
preferential flows and shallow water tables. These kind of time integrated statistics are commonly used in objective functions to calibrate and validate models. The autocorrelation length in the soil moisture time series was found to increase with depth. Its value was about 2 weeks for the soil layers within the rooting depth and increased to 2 and 3 months for layers at and below $80 \mathrm{~cm}$ depth. The cross correlation between sensors was very high for the upper soil layers, while the values decreased and were more variable for deeper layers, probably due to preferential lateral flow. The cross correlation between sensors decreased with an increase in distance, difference in texture and time averaged soil moisture between sensors. Fitting of simple or compactly supported exponential functions resulted in indicative values for the correlation length, which was found to decrease with depth. The correlation length depended on the choice of the correlation function. A correct assessment of the correlation length may help to improve and limit the calculations for state estimation or updating in space through data assimilation.

The evolution of spatially averaged soil moisture, its standard deviation and coefficient of variation in time revealed again different features of the upper layers versus the deeper soil layers. While the spatial standard deviation increased with spatially averaged soil moisture in the upper layers, it increased with decreasing wetness in the deeper layers. This was due to completely different controls in the different layers. For the deeper layers in general, a higher spatial standard deviation and coefficient of variation was found than for the upper layers. The evolution of the spatial pattern was investigated through fitting an exponential model to observed semivariance values in time. The range and sill evolved with soil moisture content in time. The inclusion of the dynamic behavior of the correlation in space is therefore expected to improve modeling and assimilation results (e.g., through dynamic propagation of the modelled state uncertainty in a Kalman filter as opposed to the static assumption in simpler methods). Pooled stratified (in time) variograms were fitted to obtain an integrated static value for the geostatistical parameters describing the spatial structure of soil moisture. Integrated over time, the sill ranged between $15-40$ vol $\%^{2}$ for upper layers and was approximately 100 vol $\%^{2}$ for deeper layers. The range reached maximal values around $200 \mathrm{~m}$ at $30 \mathrm{~cm}$ and decreased with depth to values in the order of $50 \mathrm{~m}$. The differences in characteristics for upper and lower layers indicated the need for more information (e.g., through modeling) than just upper layer observations to fully characterize the system under consideration.

The results of the spatiotemporal analysis of the soil moisture behavior in the $\mathrm{OPE}^{3}$ field revealed a complex subsurface hydrology. A better understanding of the processes in $3 \mathrm{D}$ could be achieved by combination with modeling results. However, as hydrological models often simplify reality or even neglect phenomena such as preferential flow, a careful calibration, which accounts for the observed spatiotemporal statistics, should be performed (De Lannoy et al., 2006). In the framework of data assimilation for state updating, information on the spatiotemporal behavior of soil moisture aids to determine the required spatial density of observation points: if the spatial correlation is large, a less dense network of monitoring sites is needed to update a spatially distributed soil moisture. For the $\mathrm{OPE}^{3}$ field, a maximal interdistance of $70 \mathrm{~m}$ (i.e., the correlation length beyond which the correlation becomes smaller than $1 / e$ ) can be allowed when soil moisture observations at $30 \mathrm{~cm}$ are assimilated in a field-scale model, whereas when top layer soil moisture or soil moisture in deeper layers with preferential flow is used, this monitoring network should be denser. Furthermore, the assimilation frequency depends on the temporal correlation. It was found, for soil moisture measurements within the rooting depth, that this correlation reduced to $0.368(=1 / e)$ after two weeks, whereas for deeper layers, the correlation remained higher than $1 / e$ for several months, indicating that less frequent soil moisture measurements would be needed if the assimilation happens at deeper layers, which are less sensitive to the direct impact of atmospheric forcings.

\section{Acknowledgements}

The authors thank the Beltsville Agricultural Research Center (BARC) - Agricultural Research Service (ARS) of the USDA for collecting and providing the dataset. The Hydrological Sciences Branch (HSB) of NASA/GSFC is thanked for hosting the first author during part of the research. The research is supported by a PhD-fund of the Bijzonder Onderzoeksfonds (BOF) of the Ghent University. The anonymous revierwers are thanked for their constructive comments and good advise.

\section{References}

Albertson, J., Montaldo, N., 2003. Temporal dynamics of soil moisture variability: 1 . Theoretical basis. Water Resources Research 39 (10), 2.1-2.14.

Beven, K., Kirkby, M., 1979. A physically based variable contributing area model of basin hydrology. Hydrological Sciences Bulletin 24 (1), 43-69.

Bouttier, F., 1994. A dynamical estimation of forecast error covariances in an assimilation system. Monthly Weather Review 122 (10), 2376-2390.

De Lannoy, G.J.M., Houser, P.R., Pauwels, V.R.N., Verhoest, N.E.C., 2006. Assessment of model uncertainty for soil moisture through ensemble verification. Journal of Geophysical Research 111 (D10), D10101.1-D10101.18. doi:10.1029/2005JD00636.

Dulaney, W., Daughtry, C., Walthall, C., Timlin, D., Gish, T., July 16-19 2000. Use of ground-penetrating radar and remotely sensed data to understand yield variability under drought conditions. In: European Conference on Precision Agriculture Proceedings, Bloomington, MN, CD-ROM.

Famiglietti, J., Rudnicki, J., Rodell, M., 1998. Variability in surface soil moisture content along a hillslope transect: Rattlesnake Hill, Texas. Journal of Hydrology 210, 259-281.

Famiglietti, J., Devereaux, J., Laymon, C., Tsegaye, T., Houser, P., Jackson, T., Graham, S., Rodell, M., van Oevelen, P., 1999. Ground-based investigation of soil moisture variability within remote sensing footprints during the Southern great plains 1997 (SGP97) Hydrology Experiment. Water Resources Research 35 (6), 1839-1851.

Gaspari, G., Cohn, S., 1999. Construction of correlation functions in two and three dimensions. Quarterly Journal of the Royal Meteorological Society 125, 723-757.

Georgakakos, K., Baumer, O., 1996. Measurement and utilization of on-site soil moisture data. Journal of Hydrology 184, 131-152. 
Gish, T., Dulaney, W., Kung, K.-J.S., Daughtry, C., Doolittle, J., Miller, P., 2002. Evaluating use of ground-penetrating radar for identifying subsurface flow pathways. Soil Science Society of America Journal 66 (5), 1620-1629.

Goovaerts, P., 1997. Geostatistics for Natural Resources Evaluation. Oxford University Press, Oxford.

Grayson, R.B., Western, A.W., Chiew, F.H.S., Blöschl, G., 1997. Preferred states in spatial soil moisture patterns: local and nonlocal controls. Water Resources Research 33 (12), 2897-2908.

Grayson, R.B., Blöschl, G., Western, A.W., McMahon, T.A., 2002. Advances in the use of observed spatial patterns of catchment hydrological response. Advances in Water Resources 25, 13131334.

Hamill, T., Whitaker, J., Snyder, C., 2001. Distance-dependent filtering of background error covariance estimates in an ensemble Kalman filter. Monthly Weather Review 129, 2776-2790.

Houser, P.R., Shuttleworth, W.J., Famiglietti, J.S., Gupta, H.V., Syed, K.H., Goodrich, D.C., 1998. Integration of soil moisture remote sensing and hydrologic modeling using data assimilation. Water Resources Research 34 (12), 3405-3420.

Manabe, S., Delworth, T., 1990. The temporal variability of soil wetness and its impact in climate. Climatic Change 16, 185-192.

Owe, M., Van de Griend, A.A., de Jeu, R., de Vries, J., Seyhan, E., Engman, E.T., 1999. Estimating soil moisture from satellite microwave observations: Past and ongoing projects, and relevance to GCIP. Journal of Geophysical Research 104 (D16), $19.735-19.742$.

Paltineanu, I.C., Starr, J., 1997. Real-time soil water dynamics using capacitance probes: Laboratory calibration. Soil Science Society of America Journal 61 (6), 1576-1585.

Petrone, R., Price, J., Carey, S., Waddington, J., 2004. Statistical characterization of the spatial variability of soil moisture in a cutover peatland. Hydrological Processes 18, 41-52.

Refsgaard, J.C., 2000. Towards a Formal Approach to Calibration and Validation of Models Using Spatial Data. Cambridge University Press, United Kingdom, pp. 329-354.

Robinson, M., Dean, T., 1993. Measurement of near surface soil water content using a capacitance probe. Hydrological Processes 7, 77-86.
Ryu, D., Famiglietti, J.S., 2005. Characterization of footprint-scale surface soil moisture variability using Gaussian and beta functions during the Southern Great Plains 1997 (SGP97) hydrology experiment. Water Resources Research 41, W12433.1W12433.13.

Skøien, J., Blöschl, G., Western, A.W., 2003. Characteristic space scales and timescales in hydrology. Water Resources Research 39 (10), 11.1-11.19.

Starr, J., Paltineanu, I.C., 2002. Methods for Measurement of Soil Water Content: Capacitance Devices. Soil Science Society of America, Inc., Madison, WI, USA, pp. 463-474.

Teuling, A., Troch, P., 2005. Improved understanding of soil moisture variability dynamics. Geophysical Research Letters 32, L05404.1-L05404.4.

Van Wesenbeek, I., Kachanoski, R., 1988. Spatial and temporal distribution of soil water in the tilled layer under a corn crop. Soil Science Society of America Journal 52, 363-368.

Vinnikov, K.Y., Robock, A., Qiu, S., Entin, J.K., Owe, M., Choudhury, B.J., Hollinger, S.E., Njoku, E.G., 1999. Satellite remote sensing of soil moisture in Illinois, United States. Journal of Geophysical Research 104 (D4), 4145-4168.

Walker, J., Willgoose, G., Kalma, J., 2004. In situ measurement of soil moisture: a comparison of techniques. Journal of Hydrology 293 (1-4), 85-99.

Western, A.W., Grayson, R.B., 1998. The Tarrawarra data set: soil moisture patterns, soil characteristics, and hydrological flux measurements. Water Resources Research 34 (10), 27652768.

Western, A.W., Blöschl, G., Grayson, R.B., 1998. Geostatistical characterisation of soil moisture patterns in the Tarrawarra catchment. Journal of Hydrology 205 (1-2), 20-37.

Western, A.W., Zhou, S.-L., Grayson, R.B., McMahon, T., Blöschl, G., Wilson, D., 2004. Spatial correlation of soil moisture in small catchments and its relationship to dominant spatial hydrological processes. Journal of Hydrology 286 (1-4), 113-134.

Wilson, D., Western, A.W., Grayson, R., 2004. Identifying and quantifying sources of variability in temporal and spatial soil moisture observations. Water Resources Research 40, W02507.0-W02507.10. 